\title{
PLANNING AND MANAGING THE NEGOTIATION EXERCISE
}

\author{
LARRY CRUMP \\ Griffith University, Brisbane \\ Commonwealth of Australia \\ Kyung Hee University, Suwan \\ Republic of Korea \\ L.Crump@griffith.edu.au
}

\begin{abstract}
This article introduces the negotiation exercise and the critical role of the exercise debriefing in achieving learning outcomes. This is followed by a detailed teaching plan for a negotiation exercise: The Second South American Conference on the Environment. This negotiation exercise is used to illustrate the important relationship between learning process and outcome and the critical link that the debriefing plays in achieving such outcomes. Learning objectives for the exercise include (1) comparing bilateral and multilateral negotiations, (2) examining sources of power, and (3) identifying social norms that contribute to negotiation outcomes. A number of learning points from the third objective can be highlighted during the exercise debriefing including the role that social norms play in shaping negotiation outcomes (the equity principle, equality principle, margin principle, power principle, and need principle). Learning objectives discussed in this article have been successfully achieved in many academic, commercial and governmental settings although these objectives represent but one approach. The professional teacher/trainer may use these objectives as an example in developing their own learning and teaching approach. The article concludes by presenting the views of Australian university students on the learning gained by engaging in the Second South American Conference on the Environment.
\end{abstract}

Keywords: NEGOTIATION EXERCISE DEBRIEFING, LEARNING OBJECTIVES, BILATERAL-MULTILATERAL DYNAMICS, POWER SOURCES, SOCIAL NORMS

\section{INTRODUCTION}

A learning exercise is ideal for teaching the relationship between theory and practice. One particular type of learning exercise is grounded in the field of negotiation. A negotiation exercise places substantial demands on a student's conceptual, emotional and communication systems, as they seek to answer the "what to do" question (Fells 2011). The designer of a negotiation exercise begins by identifying specific learning outcomes and then develops an exercise that effectively delivers such outcomes. Learning outcomes are often achieved after the exercise is concluded during the exercise debriefing.

This article will begin by focusing on the most important aspect of the negotiation exercise: the Exercise Debriefing. An example of a negotiation exercise is provided: The Second South American Conference on the Environment (also published within the Journal of Organizational Behavior Education) This negotiation exercise is used to illustrate the important relationship between learning process and outcome and the critical link that the debriefing plays in achieving learning outcomes.

The exercise is introduced and then a teaching plan is provided that focuses on the relationship between defined learning outcomes and the debriefing. The learning outcomes and the process 
used to achieve these outcomes serve as an example. The professional teacher/training can adopt this example or use to develop their own teaching plan and learning outcomes.

The article concludes by presenting the results of 153 Australian university students that engaged in this negotiation exercise from 2011 to 2013, and presents observation from six of these 153 students that focus on the learning these students achieved by engaging in the Second South American Conference on the Environment.

\section{THE NEGOTIATION DEBRIEFING}

We will assume that the reader understands the fundamentals of organizing and conducting the negotiations exercise. Here we will examine that aspect of the negotiation exercise that is most critical to learning: the debriefing that occurs after participants or students have engaged in the exercise. Once the negotiation exercise is introduced and conducted the instructor leads a full-class discussion or debriefing that is focused on reviewing negotiation process and outcome.

The debriefing can be fast moving and even chaotic at times. It can also be difficult to maintain order sometimes but valuable learning can be gained by examining the forces that contributed to a particular moment of disorder. The instructor searches for every opportunity to highlight learning during the debriefing.

The debriefing offers a mosaic for managing differences and searching for commonalities, as we seek to unearth knowledge and insight. Often students are forced to engage in self-reflection and sometimes this can occur in front of the entire class. The instructor must be gentle, diplomatic and use humor cautiously. Student deception, betrayal and runaway emotions are only some of the challenges that will confront the negotiation instructor as the class searches for meaning and learning. Managing group process is also required as some students will seek to dominate the discussion, other students will become lost in the details and/or miss the point entirely. Sometimes the instructor misses an important point but there is always another class where such issues can be re-examined (Mans, et al 2010; Salacuse 2010; Deason, et al 2013).

The effective negotiation debriefing includes some introductory observations or questions presented by the instructor followed by a review of negotiation outcome followed by negotiation process. The instructor must have a clear plan as to how they are going to conduct a debriefing or the debriefing will de-generate into a "muddle". The instructor imposes this pre-established debriefing plan onto class discussion so that learning can be highlighted within some kind of loose order.

The instructor should draw on specific exercise experiences and elicit reactions and encourage reflection. The instructor should explicitly link exercise experiences to course material, while concurrently offering additional knowledge, theory and insights in a spontaneous manner. It is important that the instructor foster an atmosphere conducive to open communication and learning, while the focus is to provide tools to analysis specific situations and make choices (Mans, et al 2010; Salacuse 2010; Deason, et al 2013).

The remaining part of this paper examines a specific negotiation exercise for illustrative purposes. The exercise is built around the interactions of three national governments although it would be a pretention to say that this exercise provides an inter-organizational negotiation experience, as it lacks the various components found in such setting. However, this exercise provides a robust group experience where three people (representing three organizations) come together to engage in a mixed-motive situation (competitive and cooperative forces concurrently existing). Group dynamics are fundamental to inter-organizational and intra-organizational environments, while 
XIV International Business and Economy Conference

Bangkok, Thailand, January 5-8, 2015

2015

scholars argue that the academic literature places the group within the organization (Davis 1992). From an organizational perspective this exercise is useful for examining group dynamics.

\section{EXERCISE OVERVIEW}

The author wrote this case in 2005 and has used it in a range of settings including: Australian trade diplomats (twice a year since 2010 in the Australian Trade Policy course), African government officials, Colombian diplomats, Colombian MBA students (2011-2014), Germany students engaged in a management training program (2005-2011), Korean international relations students, Turkish postgraduate students studying conflict management, and with my own MIB, MBA and undergraduate students studying international business at Griffith University.

When the author trains Australian managers and executives a similar exercise is used that changes the situation from an international conference between three nations to an environmental planning meeting between three Australian mining companies. Entitled the Fitzroy River Clean-up, this exercise is available to any professional teacher/trainer that emails the author.

The negotiation exercise entitled The Second South American Conference on the Environment (with no confidential information) is based on a coalition analysis developed by Howard Raiffa (1982) but also draws on the fundamental nature of the multilateral conference (Crump 2013; Crump and Susskind 2008).

This negotiation exercise is designed to assist a teacher/trainer to achieve several learning outcomes:

- Compare bilateral and multilateral negotiations including an introduction to negotiation complexity by examining dynamics created through a three-way negotiation.

- Examine sources of power that contribute to a negotiated outcome such as coalition building.

- Examine the power of social norms or principles that contribute to a negotiated outcome.

The Second South American Conference on the Environment is 1 x 1 x 1 three-way negotiation exercise that can result in no agreement, a three-way agreement, and a two-way agreement (with three possible variations) that excludes one party. The exercise is structured around a fictitious Latin American multilateral conference that seeks to manage water pollution on a regional basis. The Negro is the largest tributary of the Amazon River (with Brazil being downstream). Brazil, as Working Group Chair, walks out of a committee meeting with a threat to the other Working Group members (Colombia, Venezuela and Peru): this Working Group better develop a solution to the pollution problems found in the Negro River (pollution emitted from the leather industry). Colombia, Venezuela and Peru are left to find a solution during a single 40-minute period on negotiation.

Two technical studies establish (1) the rational for allocated costs and (2) gains (savings) that may be realized by choosing to cooperate in a three-way, two-way or no-way arrangement.

It is important to understand and communicate to the students/participants that costs are fixed and remain unchanged (NON-NEGOTIABLE). Savings vary depending on who cooperates with whom (see page 2 of the negotiation exercise for potential savings).

This exercise produces the most robust discussion, and some groups actually become mentally exhausted from managing 40 minutes of intense complexity. The Second South American Conference on the Environment is that rare negotiation exercise that has no confidential information. Exercise material can be distributed a week prior to class or just prior to the negotiation. 
XIV International Business and Economy Conference

Bangkok, Thailand, January 5-8, 2015

\section{AUDIENCE, SCHEDULING AND EXERCISE LOGISTICS}

This exercise requires fifteen participants minimum (five negotiations), although the exercise is regularly conducted with 90 diplomats (30 negotiations). Thirty to 45 participants are ideal (ten to fifteen negotiations), as this will produce a diversity of outcomes for discussion during the debriefing.

The exercise can be introduced, conducted and debriefed in two hours if material is distributed in and studied in advance, the group is not large (30 participants or less) and the Instructor is disciplined although $2 \frac{1}{2}$ hours allows for a richer debriefing.

Add 30 minutes if the group is large (50+ participants) and/or add 15-30 minutes if distributing exercise material on the day of the negotiation (so that participants must read, plan and then negotiate immediately).

In addition, to the exercise the following teaching material is also useful, which can be found in the Appendix to this article:

- One-page reporting sheet for each team (see Appendix A)

- Introduction to exercise (see eight slides as Appendix B)

- Debriefing exercise slides (see four slides as Appendix C)

- Negotiation results form (see Appendix D)

Since there is no confidential information, there is no need for a breakout room. Movable tables and chairs in a single room are just fine. Reserve a room that seats 60 when there are 30 participants so that there is sufficient space for both three-way meetings and two-way meetings.

Normally, when two parties decide to hold a private conversation, they get up from the table and move to a corner, next to the wall or in the hall outside the room (returning once they have an agreement or after four minutes have lapsed). This arrangement works fine for university students. When engaged to provide training to professionals, it is useful to think about where two-way negotiations might occur in relation to the three-way negotiations that are conducted at the table, as you may want to secure a sufficiently large room so that two-way negotiations can be conducted comfortably, away (but not too far away) from three-way negotiation. The coffee break area adjacent to the training room may be suitable.

This exercise is best scheduled in the second half of an undergraduate or graduate course on negotiation, although it can also be used as the initial or only case for a professional audience (executives, diplomats, lawyers, etc.) Participants should have been introduced to negotiation planning, analysis and strategy prior to conducting this case.

Reading material can be used to complement or support learning within this exercise although the critical pedagogical question is whether to assign reading prior to or after the exercise.

Some professional teachers/trainers assign reading material prior to the exercise as they prefer a deductive approach (Rules, Conclusions, Experience). Others prefer an inductive approach by assigning reading after the exercise (Experience, Conclusions, Rules). I prefer the latter as inductive learning is more likely to produce self-awareness and insight about personal motives and strategy, which is critical for a skill-building course. However, professional teacher/trainer should have a rational for the relationship between conceptual and experiential learning. This is the critical pedagogical issue.

Relevant reading material for this negotiation exercise can be found in any edition of the following two books: 
XIV International Business and Economy Conference

Bangkok, Thailand, January 5-8, 2015

- Lewicki, Roy J., David M. Saunders, Bruce Barry. Negotiation. New York: McGraw-Hill Irwin.

- Lewicki, Roy J., David M. Saunders, Bruce Barry. Essentials of Negotiation. New York: McGraw-Hill Irwin.

Recommended reading from either book includes:

- Finding and Using Negotiation Power,

- Multiple Parties and Teams.

\section{TEACHING PLAN}

Participants should come prepared, having read and analyzed the exercise material - although it is recommend that specific roles NOT be assigned until just prior to the actual negotiation. The only other material to distribute is the Team Reporting Sheet - distributed after three-person groups have been organised - which is useful for large groups (50+ participants) but not essential for smaller groups. Following is a list of teaching procedures.

1. One to two weeks prior to the exercise, hand out the exercise material and advise students/participants to attend the exercise with a calculator.

2. On the day of the negotiation, provide brief introductory comments based on the Learning Objectives (5-15 minutes). Participants who have arrived prepared usually want to play Colombia, as this role appears to have the most power (although not everyone perceives it this way). It is useful to point out (without disclosing that Colombia may be perceived to have the most power) that it is easy to negotiate with power but if you want to learn how to manage power in a negotiation, then it may be advantageous to seek to play the least powerful role (many participants perceive Peru to have the least power in this exercise). It is best to assign participants to roles in a random manner (described shortly) without allowing for personal preferences.

3. Review the critical information contained in the accompanying slides (15 minutes). See Appendix item B.

3.1Introduction to Negotiation Exercise

3.2Negotiation Simulation Rules

3.3 Role Assignment

3.4 Negotiation Exercise

3.5 Fixed Cost to Solve a Water Pollution Problem

3.6 Negotiation is about Savings via Cooperation (NOT Costs)

3.7 Procedural Rules

3.8 Reporting Sheet (optional slide)

Perhaps the most important points in reviewing the critical information are to (1) outline the procedural rules (slide 3.7) and (2) clearly communicate that the exercise is not about how much money will be spent (costs are a non-negotiable fact in the case), but rather about how much might be saved through a three-way and/or various two-way cooperative arrangements. Parties save no money $(\$ 0)$ if they decide not to cooperate or fail to reach an agreement in the allocated time (slides 3.5 and 3.6). Although this issue of costs and savings is clarified in writing and then discussed in the exercise introduction, don't be surprised to find that costs still become an issue in some negotiations.

4. Organizing to negotiate (10 minutes) 
4.1 Invite participants to form groups of three at a single table.

4.2 Once all participants are seated in triads (teams), place one Colombia role (green paper), one Venezuela role (blue paper) and one Peru (pink paper) face down at each table so participants cannot see the assigned (XXX) role. Instruct participants to select a paper and then spend five minutes thinking about playing this specific role (here we assumed that students/participants have arrived having studied the case).

4.3 Note: if this is the first time students/participants have seen the case then they will require 15 to 30 minutes to prepare.

5. The instructor floats around the room and is available to answer questions throughout the 40minute exercise.

6. Peru is assigned to submit the Team Reporting Sheet to the instructor (see Team Reporting Sheet handout - Appendix A).

7. A 10-minute break can follow the exercise (so participants who finish early will have a longer break). During the break, the instructor writes all the outcomes from the reporting sheet on the white board or inputs the data into a Word or Excel document (see Negotiation Results form Appendix D)

8. Debriefing: 40-60 minutes, depending on group size

\title{
6 EXERCISE DEBRIEFING
}

Please note that the framework provided for debriefing this exercise is but one approach and serves as an example. The professional teacher/trainer may adopt this approach or develop their own approach based on the example present here.

We will use negotiation outcomes procured at Griffith University to assist us in illustrating how to debrief this negotiation exercise. First, it will be useful to establish the demographic characteristics of the student population. All 153 students (51 negotiation exercises) attend Griffith University and were enrolled in International Business Negotiation (3014IBA) in $2^{\text {nd }}$ semester 2011, 2012 or 2013. International Business Negotiation is a $3^{\text {rd }}$ year elective in a Bachelor of International Business degree. Table 1 provides a breakdown of demographic data for all students enrolled in the Griffith University Bachelor of International Business on the Nathan Campus (the campus where data was gathered). The demographic data in Table 1 is self-explanatory.

TABLE 1

\section{Griffith University 2013 International Business student demographics}

\author{
Gender: \\ Female: $45 \%$ \\ Male:55 \% \\ Age: \\ $30+5 \%$ \\ $25-2919 \%$ \\ $24-2061 \%$ \\ $-1914 \%$ \\ Nationality: \\ Australian:49\% \\ Northeast Asia30 \% \\ Southeast Asia $4 \%$ \\ Americas: $6 \%$
}


XIV International Business and Economy Conference

Bangkok, Thailand, January 5-8, 2015

Europe: $6 \%$

Other $5 \%$

Any debriefing flows smoothly with a structured debriefing plan. Some instructors prefer to begin by presenting a set of questions and other instructors may prefer to present information focused on critical aspects of the exercise or provides a framework or context for understanding the exercise. Regardless of the approach that is taken it is important that the instructor have a rational for the adopted approach. The following approach serves as one example that can be adopted or used as an example to develop several other learning and teaching approaches.

It is helpful now to take a look at:

- Debriefing Negotiation Exercise (Slides 1-4, Appendix C)

- Negotiation Exercise Results form (Appendix D)

- A Sample of Negotiation Exercise Results - International Business Negotiation (3014IBA) Griffith University, 2011-2013 (Appendix E)

This exercise normally releases a substantial amount of psychological energy, so the first challenge is to get the entire group to sit quietly and listen. Providing outcome data to the class will briefly produce order, as student begin to compare their outcome to the outcome achieved by others.

\subsection{Data accuracy}

First, it is useful to confirm whether each team's outcome is correctly recorded (data-reporting problems or data-entry problems do occur). Then take control of the group and explain that many of these outcomes will be reviewed but first it will be useful to compare bilateral and multilateral negotiations.

\subsection{Two party, multiparty and complexity}

Ask student to briefly consider the same facts but without Colombia. What insights can be gained by converting this case into a two-party negotiation? Slide 2, Appendix $\mathrm{C}$ will be useful for managing a response to this question along with the following:

Peru and Venezuela will seek to distribute $\$ 500,000$ in savings based on the fact that Venezuela will spend \$3 million and Peru will spend \$2 million.

A bilateral negotiation containing this structure will likely produce a bargaining range of between $\$ 200,000$ and $\$ 300,000$. We can say with some certainty that outcomes will not normally fall outside of these assumed resistance points.

In addition, we can also use intelligent guesswork to assume that parties might apply an equality principle (50/50) so that each receives $\$ 250,000$ of the potential savings (depending on Peru's negotiation skill or Venezuela's generosity) or these two parties may apply an equity principle (balance between input and output) and split savings via a 40/60 arrangement - given Venezuela's input of $\$ 3$ million and Peru's input of $\$ 2$ million (with Venezuela receiving $\$ 300,000$ in savings and Peru receiving $\$ 200,000$ in savings).

Certainly other outcomes are possible, but it is likely that any other outcome will remain within the $\$ 200,000-\$ 300,000$ bargaining range.

This imaginary two-party negotiation - although complex - is fairly predictable. But add a third party (Colombia) to this exercise, and our ability to predict the bargaining range or the outcome quickly diminishes because of increasing complexity (see slides 2 and 3, Appendix C). 
Now, each party has five possible outcomes and multiple alternatives. These alternatives increase complexity to the point that it becomes difficult to predict the outcome.

Wrap-up this presentation on negotiation complexity and announce that we now wish to review the negotiated outcomes that have resulted from this exercise - but first take a quick vote.

\subsection{Sources of power and negotiated outcome}

The recommended reading material, presented previously, provides a detailed discussion on sources of power (drawing on the classic work of French and Raven, 1959). This reading material should be reviewed in the first class after the exercise is conducted.

The following questions are useful for starting the next part of the debriefing. A quick vote via a show of hands:

- Who thinks Peru is most powerful? Who thinks Peru is least powerful?

- Who thinks Colombia is least power? Who thinks Colombia is most powerful?

- Who thinks Venezuela is in between Colombia and Peru in terms of power?

Unanimous agreement will not be observed, but generally 90 percent will say that Colombia is most powerful and Peru is least powerful.

Advise participants that we want to examine sources of power more closely and then start by moving into debriefing the negotiation exercise by going to specific teams and asking to comment on their negotiation outcome (and if time allows their process).

As the debriefing proceeds the Instructor will find that certain issues are raised that are captured by the following questions:

- Where does power come from?

- How did you use power in this exercise?

- How did others use power?

- Did power change or shift as the negotiation unfolded?

- What did you do to increase your own power or decrease the power of others as the negotiation unfolded?

1 Social norms that contribute to outcomes

This debriefing is particularly useful for focusing on specific social norms and how these norms can be converted into sources of power. When a social norm becomes a source of power we establish a rule or principle as a means of highlighting this dynamic.

In addition, some social norms appear to be more or less salient, given the facts and circumstances of a particular negotiation. This case is no exception, with some social norms more salient than others.

This section will consider the relevance of five social norms as sources of power within a negotiation: the equity principle, the equality principle, the margin principle, the power principle and the need principle (a principle is a rule).

2 Equity principle

Given the prior discussion on equity and equality (in examining negotiation complexity), it is useful to begin by reviewing negotiation outcomes that illustrate application of the equity norm. 
XIV International Business and Economy Conference

Bangkok, Thailand, January 5-8, 2015

The "equity principle" (in this case, a balancing between input and output) is highly salient in this exercise (see Ravin et al. 1998 and the "legitimate equity norm" or Walster et al 1978).

When we divide $\$ 1,210,000$ in savings (gained from a three-way deal) by 50 percent, 30 percent and 20 percent, we arrive at the following: Colombia \$605,000; Venezuela \$363,000; Peru $\$ 242,000$.

Please see Teams 18, 30, 43, 44, 46, 48, 49, 52, 53 and 56 (Appendix E: A Sample of Negotiation Results) as examples of the application of this meaningful norm. Please note that 10 out of 51 total negotiations (20 percent) in this three-year sample produced an outcome based on the Equity principle (50 / 30 / 20 division of available benefits through cooperation).

The equity principle is certain to appear in this negotiation exercise, as the circumstance of the exercise seem to be salient for this particular solution. It is useful to spend some time reviewing negotiation process for Equity outcomes as some negotiations occur very quickly (probably no two-way negotiations occurred) and other negotiations go to the deadline (significant two-way negotiations normally occur).

The instructor may not have time to explore all outcomes guided by an Equity Principle, as there is so much more to review.

\section{Equality principle}

The "equality principle" is NOT salient under the facts and circumstance of this exercise, but it does appear. See Teams 6 and 54 (Appendix E). If the equality principle is applied, then it is useful to look carefully at the dynamics, as one of the parties probably focused on the importance of longterm positive relations (the exercise does not ask participants to consider relations between nations, but nor does it forbid such considerations), while the other parties may feel a strong sense of affinity with equality (perhaps because these parties have previously experienced discrimination). It is a rare but interesting outcome in this exercise (see Raven, et al 1998 and "legitimate reciprocity" or Goulder 1960 and "reciprocity as a universal moral norm", each of which may be related to the equality principle).

Please note that 2 out of 51 total negotiations ( 4 percent) in this three-year sample produced an outcome based on the Equality principle (1/3 $1 / 3 \quad 1 / 3$ division of available benefits through cooperation).

\section{Margin principle}

The world is unfair - but so what!

When subtracting a three-way outcome $(\$ 1,210,000)$ from a two-way outcome involving Colombia and Venezuela $(\$ 1,180,000)$ the difference is $\$ 30,000$. We call this difference the "margin principle", as it represents the difference (or margin) between the three-way outcome and a two-way outcome that excludes Peru.

Here is the part that appears unfair to many (through not all) participants: Peru contributed 20 percent of the cost of solving the pollution problem ( $\$ 2$ million) but that does not matter in Rafffa's (1982) world. As in life, a party's input does not always justify the output they might expect at the negotiation table (all that hard work for nothing). Under this frame, we are reminded that bringing value to the table does not assure that we will leave with equal or greater relative value. Fair or unfair, sometimes parties walk away with less, relative to where they began. 
An informed Peru will hope that other parties do not realize the reality of the $\$ 30,000$ margin and a strategic Peru will steer parties away from this reality, but an astute and/or exploitative Colombia and/or Venezuela can quickly do the math. If Peru cannot build an alliance based on equity, friendship or some other principle, then Peru is left to flutter in the wind (see Teams 2, 7 and 27, Appendix E). From this frame, anything greater than $\$ 30,000$ is a win for Peru.

Sometimes we find teams that think about the apparent injustice imposed upon Peru through the application of the Margin principle although the principle is still applied. In this case we find outcomes where Colombia or Venezuela decided to give Peru some token addition funds as a way to maintain good relations or to alleviate their own guilt for appearing so exploitive. Team 4 is one example, as Peru received 37,000 or Team 29 where Peru received $\$ 31,000$. In each case the Margin principle was recognised but then slightly adjusted to accommodate secondary interest. It is interesting to ask these team why Peru got a bit more than $\$ 30,000$, as it produces insightful understanding about individual and group dynamics.

Sometimes we find that Colombia and Venezuela will each decide to take a bit more from Peru, although Peru has contributed 20 percent to the solution and the "margin" is actually $\$ 30,000$. Observe Team 1 (Appendix E), where Peru has been left with $\$ 10,000$. Colombia and Venezuela each acknowledged the $\$ 30,000$ that Peru brings to the table and then take $\$ 20,000$ off of Peru by leaving Peru with only $\$ 10,000$ (Colombia and/or Venezuela are really being very exploitive in this case). Or take a look at Team 24 where Colombia and Venezuela were slightly less exploitive by offering Peru $\$ 15,000$.

Please note that 7 out of 51 total negotiations (14 percent) in this three-year sample produced an outcome based on the Margin principle or its variation with 3 out of 51 presenting an established rational for Peru's outcome $(\$ 30,000$ outcome exists as a clearly logical outcome given the Colombia + Venezuela split vs. a three-way split) and 2 out of 51 produced exploitive outcomes (4 percent) by leaving Peru with less than $\$ 30,000$.

In some cases Peru was offered $\$ 30,000$ and this party replied by saying that their input was 20 percent and so $\$ 30,000$ was simply unacceptable and so they would prefer to take nothing rather than accept an outcome that establish an exploitive precedent that might impact on their future relations with these two parties. Please see Team 14, 25, 31 and 33. On the other hand, sometimes Colombia and Venezuela put together their two-way deal (dividing $\$ 1,180,000$ ) and then the negotiation is over without anyone - even Peru - saying, "But wait a minute - there is still $\$ 30,000$ of value remaining on the table that could be allocated to Peru or someone." This is simply an illustration of poor analysis. Sometime this later process explains why Peru ends-up with $\$ 0$.

5 Power principle (shared perceptions of power)

Sometimes a party ends-up with $\$ 0$ (and this can apply to any of the three parties) because that party made the other two parties so angry (by actively forming and then walking away from a coalition, for example) or that party is so "unlikeable" that the other two parties happily build a coalition against such a party. In this case, part of the outcome is based on dividing whatever saving is available, and it is also based on the joint satisfaction of "doing in" the excluded "unlikeable" party. Team 22 is an example of this group dynamic. Venezuela first formed a firm coalition with Peru (through a 2 way private meeting) and then Colombia made an attractive counter-offer to Venezuela in a 3-way meeting that was accepted, which so angered Peru that Peru proceeded to convince Colombia that Venezuela could not be trusted. Colombia and Peru reached an agreement to divide $\$ 840,000$ thus excluding Venezuela from any cost savings (it is interesting 
to note that Team 22 Colombia and Peru each took only slightly less than what would have been gained through a 3-way equity split).

A stable two-party coalition contains substantial power in this case. The challenge lies in creating a stable coalition, as Colombia and Venezuela each have resources (embedded within each alternative outcome) to continually make counter-offers that can destabilize a coalition that includes Peru.

The math in Raiffa's (1982) brilliant game provides Colombia with resources that allow Colombia to destabilize a Venezuela-Peru deal. For example, Peru can offer Venezuela $\$ 470,000$ of the $\$ 500,000$ available in savings (with $\$ 30,000$ for Peru). But Colombia, if it wishes, can offer Venezuela a 50/50 split on $\$ 1,180,000$ (or $\$ 590,000$ each). But then Peru can come back and offer Colombia $\$ 800,000$ of the $\$ 840,000$ available in savings (with Peru gaining $\$ 40,000$ ). Venezuela can come back with a counter-offer to Colombia ... and it can go on and on and on...

In some negotiations, the number of possible alternatives and outcomes is mind-numbing. Parties go around and around with offers and counter-offers.

Any outcome that excludes Colombia or Venezuela should be explored carefully, as something interesting happened here. We do not find an outcome with Colombia receiving $\$ 0$ in these 51 undergraduate negotiations but such outcomes have been observed in negotiations involving trade diplomats and company managers. In such cases, Venezuela and Peru will try to dictate terms to Colombia (you will take $\$ 100,000$ or you will gain $\$ 0$ ) and Colombia eventually said it would prefer nothing. So Venezuela and Peru split $\$ 500,000$ based on an equity principle $(\$ 300,000$ and $\$ 200,000)$.

Or more interestingly, imagine when Venezuela and Peru succeeded in establishing a stable coalition and then seeks to dictate terms to Colombia. Unable to break this coalition, Colombia can end-up negotiating a final offer of $\$ 250,000$ (an amount that was more attractive than $\$ 0$ ). Such an outcome results in Venezuela and Peru dividing $\$ 960,000(\$ 1,210,000-\$ 250,000=$ $\$ 960,000$ ) rather than $\$ 500,000$ (which Peru and Venezuela would have gained in a normal twoway deal).

These are pretty interesting negotiation dynamics and if they occur - an instructor can note - a potentially dangerous game when two apparently weaker parties succeed to impose their will on a party that is apparently more powerful (imagine the outrage this more powerful party might feel). This analysis recognizes that parties have a future (see Crump 2007), and so may have an opportunity to negotiate with either party on other issues some day in the future.

A Venezuela-Peru coalition may gain greater stability if these two parties find a rational argument that justifies their preferred outcome. Occasionally, such a coalition might argue that Colombia is the largest polluter and should not be rewarded but should be punished through this exercise. Essentially, a Venezuela-Peru coalition is reframing the negotiation from a "cost and savings" frame to a "punish polluters" frame. Either frame can be promoted, depending on how a party interprets case facts, while each frame favors one party over another.

This aspect of the case, although rare, does demonstrate the relationship between reframing and shifting power relations. The margin principle, when compared with the equity principle, also represents a choice between two frames, with power relations shifting dramatically based on the frame that eventually is adopted (see Crump 2005; Crump and Druckman 2012).

6 Creative solutions 
Re-framing can be taken one step further when two parties try to convince a third party to remain in the game (agree to cooperate) but accept $\$ 0$ thus two parties can divide the maximum amount available. Teams 21, 47 and 55 are each examples of this "creative solution". But each outcome is structured with slight but significant differences. In the case of Team 21 we find Colombia and Peru dividing the maximum amount (each receiving $\$ 605,00 \times 2=\$ 1,210,000$ ) with Venezuela receiving $\$ 0$ but during the debriefing Venezuela denied that it had agreed to accept $\$ 0$ and so this outcome collapsed. Apparently, Venezuela had been offered nothing in exchange for accepting \$0 - a valuable lesson for all parties and the entire class.

In the case of Team 47 and 55 Peru reported in the debriefing that they had willingly accepted $\$ 0$, as Colombia and Venezuela agreed that the pollution control plant would be built in Peru (thus Peru traded short-term economic advantage for long-term economic advantage). An interesting and unusual outcome that happened twice in one class because Team 47 and Team 55 were seated near each other and so one team over-heard the outcome of the other team thus demonstrating the power of solution migration in negotiation process and outcome (Crump 2010). But note the differing outcomes for team 47 and 55. In the former case the benefits of cooperation were divided $50 / 50$ and in the later case such benefits were divided 62/38, which demonstrates clear differences in individual negotiation skill when these two cases are compared. Such observations are interesting to explore but often there is insufficient time to examine such micro-level moves. There is so much more in Appendix E, but this highlights some of the important issues and provides a sample of what is possible in using this negotiation exercise for teaching and learning purposes.

\section{Need principle}

The need principle does exist (referred to as the "legitimate dependence norm" by Raven et al. 1998 and "responsibility and dependence" by Berkowitz and Daniels 1963), but it has never been observed in this exercise. Peru has never argued that it is actually the smallest, poorest nation, and so in greatest need.

Facts and circumstances seem to determine the principles or social norms most salient in a specific negotiation. The need principle may be salient in other negotiations, but not this one.

The power principle, equity principle and margin principle are very common within this exercise, with the equality principle observed rarely. Re-framing (costs and savings vs. punishing polluters) to shift power relations is also a very viable strategy (especially when combined with coalition building) but rarely observed.

8 Results: Social norms and negotiated outcomes

The results presented are only preliminary and based on a sample of 51 exercise (153 students) over three years in an undergraduate international business program, but the outcome from this learning exercise offers interesting results. Table 2 is self-explanatory and provides an overview to the outcomes previously discussed.

TABLE 2

Social norms and negotiate outcomes

Equity principle 20 percent

$(\mathrm{N}=10 / 51)$ 
XIV International Business and Economy Conference

Bangkok, Thailand, January 5-8, 2015

Equality principle 4 percent

$(\mathrm{N}=2 / 51)$

Margin principle and its variation14 percent

$(\mathrm{N}=7 / 51)$

Margin principle + exploitation 4 percent

$(\mathrm{N}=2 / 51)$

Need principle 0 percent

$(\mathrm{N}=0 / 51)$

Most outcomes are not explained by any of the social norms previously reviewed. Power relations, individual bias and perception, interpersonal and group dynamics and negotiation process come together to create a complicated set of decision making dynamics, which are managed via negotiation knowledge and skill. Ultimately, power and the perception of power seem to determine outcomes although in this case there are three parties that shape the process leading to an outcome.

Many of the outcomes that are not reflected through Table 2 are a result of the application of the Power principle. In this case Colombia is generally perceived to have more power, Peru is generally perceived to have less power with Venezuela somewhere in between. Establishing clear distinctions in the application of the power principle is difficult without data that is more carefully gathered (beyond what is produced through outcomes at a negotiation exercise debriefing).

Nevertheless, we can say with some certainly that 20 percent applied the Equity principle, 4 percent applied the Equality principle, 14 percent applied the Margin principle and its variation with 4 percent (embedded in the 14 percent) engaged in clearly exploitive behavior. No outcome has ever demonstrated the Need principle in the Second South American Conference on the Environment.

\section{DEBREFING WRAP-UP}

- Note that this exercise allowed us to compare bilateral and multilateral negotiations, which serve as an introduction to negotiation complexity by examining dynamics created through a three-way negotiation.

- The exercise also provides understanding about the power of social norms that can contribute to a negotiation outcome.

- And the exercise allowed us to look at power more broadly.

- Review Slide 4 (Appendix C - Debriefing Negotiation Exercise) on Sources of Power.

Sources of Power (Appendix C, slide 4), begins by recognizing that preparation and analysis serve as a source of power although within a negotiation this advantage may only be temporary. To negotiate effectively requires that one's analysis be used to persuade the other side and in the process of persuading the other side is being educated as to what is possible or not possible. Sharing of information serves to transfer power.

Attributes: We all arrive at the negotiation table with certainly attributes that can include personal knowledge, skills and ability. Being young or old, being male or female, and/or having other 
attributes relevant to a particular goal (if the goal is to solve a pollution problem then an environmental engineer would have an advantage over a electrical engineer - all other things being equal) serve as a source of power.

Value: Bringing value to the table is normally a source of power because a negotiation often involves trading or sharing. If you own value then this is something that others will want to have access to and so this dynamic produces dependency. When others are dependent upon you (because you have value to trade or share) it serves as a source of power. In this case Colombia spends more (\$5 million) and this spending logically results in their ability to save more (or others have a perception that Colombia should save more). Colombia gains power because of the logical relationship between spending and saving since this negotiation is about saving and sharing savings. Point three (slide 4, Appendix C) highlights this point.

Social Norms: Strategically applying accepted social norms or principles (rules) serves as a source of power. The power of the equity principle (input - output) is especially apparent as the debriefing unfolds. Often we also see the application of the margin principle or its variations. Occasionally we find the application of the equality principle but never find the application of the need principle (it is a useful principle in other situations). In all other cases the power principle serves as a source of power and plays a very important role in negotiation process and outcome. This is why we almost always see a pattern where Colombia gaining the most, followed by Venezuela and followed by Peru.

Coalitions: Two parties can dictate terms to a third party if the coalition can remain stable. In this exercise some groups form and break and form and break coalitions, but most often all three parties agree to work together although these parties must then find a solution that is acceptable to all. Coalition dynamics are prominent in this exercise and can be highlighted as a source of power. The frame that is adopted can dramatically shift power relations (Crump 2005). The Equity Principle, the Equality Principle and the Margin Principle each serve as a source of power (ground in widely accepted social norms) that also frames the negotiation exercise in the context of answering the crucial question: What is a fair outcome? Clearly, if Peru is able to frame the negotiation through the equality principle they are set to gain the most, followed by the equity principle. If the other parties frame the exercise as a Colombia - Venezuela deal plus what ever value Peru might add then Peru's outcome is far less advantageous.

Parties can agree to frame the negotiation as a "cost and savings" exercise (and most negotiations adopt this frame) but Peru and Venezuela can also agree that the largest polluter should not gain a reward but should be punished. Framing the negotiation in this manner can result in substantial power being shifting from Colombia to a Venezuela - Peru collation. Substantial outcome value followings if the Venezuela - Peru coalition remains stable throughout the end-stage of the negotiation.

Slide 4 (Appendix C) is the wrap-up slide that can be used to illustrate these points, however there are many approaches that can be taken via this exercise and the Instructor is invited to find that approach that makes sense. The debriefing approach outlined here simply serves as an example that might help professional teachers/trainers to develop their own approach and material.

\section{STUDENT LEARNING FROM EXERCISE}

We will conclude our review of planning and managing the negotiation exercise by reviewing the reflections of 2013 international business negotiation students on what they learned from The 
XIV International Business and Economy Conference

Bangkok, Thailand, January 5-8, 2015

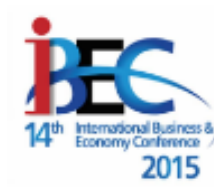

Second South American Conference on the Environment. We will consider (1) the acquisition of deep personal understanding, (2) mastering negotiation strategy, and (3) linking theory to practice.

\subsection{Gaining deep personal understanding}

Venezuela (Team 50) was part of a three-way outcome that resulted in Peru gaining an amount equal to 20 percent (a variation of the equity principle) with Colombia and Venezuela applying the equality principle in dividing the remaining amount (each secured \$484,000). Interesting dynamics. Venezuela (Team 50) observed:

"When these two countries [Colombia and Peru] started working together and deciding whether to leave Venezuela out of the discussion that's when I felt as if I was losing control of the debate. I couldn't think quickly on my feet of different ways that I could counteract Colombia and Peru leaving Venezuela out of the talks because I hadn't taken into consideration that that could be a possible approach to solving the issue...I immediately resorted to using hardball tactics and threatened Peru and Colombia's ties with Venezuela. I think the fact that I opted for this kind of tactic without even realizing it is a key sign that I didn't manage conflict effectively. I instantly became defensive instead choosing to taking some time to think about what this would mean for each country and how I could counteract their suggestion more effectively...I acted extremely self-oriented for exactly the reason stated above so when we got to the agreement stage and should have selected the best solution my brain couldn't see through the fog to take into account the other parties suggestions."

It is useful to note that of 18 students that played the role of Venezuela in 2013 this particular student achieved the second largest outcome (See Appendix E, Venezuela Team 50), but this student is not caught up boasting about their success rather this student is beginning to examine their motives and the negotiations techniques that supported goal acquisition. Helping a student to conceptualize and ask such questions can produce life-changing moments. The personal attributes of the negotiator are fundamental to negotiation process. Reflection on who we are and why we do what we do is time well spent. Negotiation exercises have the potential to produce this kind of deep insight.

\subsection{Mastering negotiation strategy}

Of 18 students representing Peru in 2013 the student representing Peru in Team 42 achieved the largest outcome by gaining $\$ 410,000$. Here is what Peru (Team 42) observed:

"In this negotiation I learnt that it was important to build some kind of rapport with both Colombia and Venezuela, as otherwise the two larger nations would walk all over me. I also learnt that it can be helpful to sit back and see how the two other parties negotiate, and try and determine their motives. I noticed that Colombia was wanting to have as much money as possible, and that Venezuela was very much wanting to be as fair as possible. With this knowledge I quickly befriended Venezuela, and tried to put my argument/s in a fair light."

Peru (Team 47) achieved no money (\$0) but secured an agreement to build the plant in Peru thus gaining construction and plant operational employment. Peru (Team 47) states: "The main things I learned about negotiation process was that it is very effective if you can find a way to avoid a 
head to head collision of interests. For example, I think the negotiation went well because I chose to focus on an issue that I knew that Colombia and Venezuela wouldn't be focusing on. This way we didn't all fight for one resource and were able to spread the benefits between the three countries."

In Team 42 and 47 the "weakest" party were each able to secure a valuable outcome by engaging in strategic action. They began by observing and gathering information within a theoretical framework and then analysing that information to make on-the-spot decisions about actions to take and actions to avoid. Building and reinforcing strategic skill is fundamental to negotiation teaching and learning. Strategy is not only about effectively managing affairs in the present but also requires some understanding of actions taken today and their future implications.

Such insights are not so significant for the experienced professional but it is important to understand that the large majority of these students are in their early 20's. Such knowledge represents important learning about the use of strategy from a theoretical and practical perspective. Venezuela (Team 52) states: "The logic may be that a decision today, creates a precedence tomorrow, and setting a precedence can be a strong source of power." Colombia (Team 52) voiced similar concern about how a \$30,000 outcome for Peru would establish an exploitive precedent that may be undesirable for future three-way relations. Team 52 applied the Equity principle to achieve their outcome based on this understanding. Venezuela (Team 41) did not apply the Equity principle but offers similar observations: "As the negotiation was concluding I realised I should have pushed Peru for more money as I was representing the interests of Venezuela. I have since learnt that money is not the only sign of success in a negotiation i.e. the relationship between Colombia, Venezuela and Peru is extremely important." Each student is recognising and confirming the important relationship between the present and the future, and that negotiators must operate in multiple-dimensions when engaged in strategic actions.

\subsection{Linking theory to practice}

Peru (Team 58) is part of a three-way agreement that provided Peru with $\$ 80,000$, Venezuela with \$430,000 and Colombia with \$700,000 (See Appendix E). Peru (Team 58) observed:

"As soon as I heard I was Peru I felt defeated, before even sitting down to the table. I had this preconceived notion that Peru was completely powerless and would have no say in the dealings of the negotiation. A minute into the negotiation when Venezuela and Colombia had their [one-on-one] meeting, the fear was realized. It was when they came back to the table that I decided I wasn't going to let it go without a fight... By building a coalition with Venezuela I knew as long as it was a strong one we could pressure Colombia and shift the power in our favour and get more for our countries, completely flipping the negotiation around... We had the right approach down but no reasoning to back it up...Throughout the process Colombia kept saying how she spent more so she should get more, and all that time we could've been saying, yeah, you spent more because you're polluting more, and therefore you shouldn't be rewarded for that. If only I had thought to frame it like that during the negotiations!...It's incredible what can be achieved by forming a coalition and shifting the power. I only wish we would've had some reasoning/support to back it up."

The "reasoning/support" that Peru (Team 58) is referring to actually involves the relationship between theory and practice. Initially, negotiation students study the theory of strategy, planning 
XIV International Business and Economy Conference

Bangkok, Thailand, January 5-8, 2015

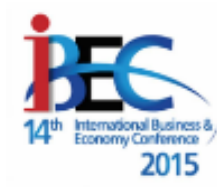

and analysis before they move into framing, shifting power relations and coalition building. Peru (Team 58) had sufficient knowledge to appreciate that these theories can be combined together to guide strategic action. In this case, understanding framing and re-framing (cost and savings vs. punishing polluters) and then using a re-framed issue as the rational to support coalition formation to secure a shift in power relations (to control outcome decisions) involves several complicated theoretical processes (see Crump 2005; Crump and Druckman 2012). It is one thing to gain such theoretical understanding and another to be able to apply the theory at the right time and in the correct manner. Peru (Team 58) demonstrates strong motivation to understanding and apply theory. Negotiation exercises regularly provide students with the opportunity to a apply theory or help students to understand how theory can be applied.

Those of us in academia are very concerned with theory but we are equally concerned with theory relevance and the application of relevant theory. After a lecture in the physical sciences a teacher and their students enter the laboratory to apply theory and observe the implications of theory application. The negotiation exercise is a fluid and even chaotic environment that places substantial demands on students' cognitive, emotional and communication systems. The negotiation exercise represents a real laboratory that complements course lectures and readings.

\section{NOTE}

I am grateful to the blind-reviewer that offered comments through the XIV International Business and Economy Conference (Bangkok, January 2015). I am also grateful to Bruce Barry, who first invited me to prepare teaching notes for the Second South American Conference on the Environment (the exercise is found in the 2015 edition of Negotiation: Readings, Exercises and Cases ( $7^{\text {th }}$ ed.) by Roy J. Lewicki, Bruce Barry and David M. Saunders) although this paper has evolved substantially since that first draft. I very much appreciate the assistance and support of all reviewers that offered assistance although I am responsible for any errors or omissions found in this article.

\section{REFERENCES}

Berkowitz, L., \& Daniels, L. R. (1963). Responsibility and dependence. Journal of Abnormal Psychology, 66(5), pp. 429-436.

Crump, L. (2005). For the sake of the team: Unity and disunity in a multiparty Major League Baseball negotiation. Negotiation Journal, 21(3), pp. 317-341.

Crump, L. (2007). A temporal model of negotiation linkage dynamics. Negotiation Journal, 23(2), pp. 117-153.

Crump, L. (2010). Strategically managing negotiation linkage dynamics. Negotiation and Conflict Management Research, 3(1), pp. 3-27.

Crump, L. (2013). International trade negotiations. In Olekalns, M. and Adair W. (eds) Handbook of Research in Negotiation, Cheltenham, UK: Edward Edgar, pp. 387-415. 
XIV International Business and Economy Conference Bangkok, Thailand, January 5-8, 2015

Crump, L., \& Druckman, D. (2012). Turning points in multilateral trade negotiations on intellectual property. International Negotiation, 17(1), pp. 9-35.

Crump, L., \& Susskind, L. E. (2008). Multiparty Negotiation: Organizational and International Negotiation (vol 4). London: Sage in association with the Program on Negotiation at Harvard Law School.

Davis, J. H. (1992). Introduction to the special issue on group decision making. Organizational Behaviour and Human Decision Processes, 52(1), pp. 1-2.

Deason, E. E., Y. Efron, R. Howell, S. Kaufman, J. Lee, \& S. Press. (2013). Debriefing the Debrief. Working Paper Series (no. 202), Center for Interdisciplinary Law and Policy Studies at Moritz College of Law, Ohio State University.

Fells, R. (2011). Using visual metaphors and images as a way of teaching a practical approach to negotiation. Journal of Organizational Behavior Education, 4, pp. 5-22.

French, J. R. P. and Raven, B. H. (1959). The bases of social power. In D. Cartwright (ed.), Studies in social power (pp. 150-167). Ann Arbor, MI: Institute for Social Research.

Gouldner, A. W. (1960). The norm of reciprocity: A preliminary statement. American Sociological Review, 35(2), pp. 161-178.

Lewicki, R., Saunders, D., \& Barry, B. (2015). Negotiation: Readings, Exercises, and Cases $\left(7^{\text {th }}\right.$ ed.). New York: McGraw-Hill Irwin.

Mans, U., Shimshon, G., \& Suransky, L. (2010). Training the warrior-diplomat: Enhancing negotiation and conflict management skills through experiential learning. International Negotiation, 15(2), pp. 247-280.

Raiffa, H. (1982). The Art and Science of Negotiation. Cambridge, MA: The Belknap Press of Harvard University Press.

Raven, B. H. (1993). The bases of power: Origins and recent developments. Journal of Social Issues, 49(4), pp. 227-251.

Raven, B. H., Schwarzwald, J., \& Koslowsky, M. (1998). Conceptualizing and measuring a power/interaction model of interpersonal influence. Journal of Applied Social Psychology, 28(4), pp. 307-332.

Salacuse, J. W. (2010). Teaching international business negotiation: Reflections on three decades of experience. International Negotiation, 15(2), pp. 187-228.

Walster, H. E., Walster, G. W., \& Berscheid, E. (1978). Equity Theory and Research. Boston MA: Allyn \& Bacon. 
XIV International Business and Economy Conference

Bangkok, Thailand, January 5-8, 2015

\begin{abstract}
Appendix
Second South American Conference on the Environment
\end{abstract}

Appendix A:

Team Reporting Sheet (Handout one sheet per team)

Team Reporting Sheet

*Team 


\section{Reporting Sheet (Cost Saving Division)}

Colombia \$ + Venezuela $\$$ + Peru $\$$ $=$ Total $\$$

* Please Note: Peru is responsible for recording the outcome (the amount saved) and submitting this document to the Instructor after the negotiation ends.

\section{Appendix B: \\ Introduction to Negotiation Exercise (8 slides)}

$\begin{array}{cl} & \text { Negotiation Simulation Rules } \\ \text { Introduction to Negotiation Exercise } & \text { - If you can not stay for the entire negotiation } \\ \text { (40 minutes) then tell the instructor that you } & \text { can NOT take a role } \\ \text { - Be yourself }- \text { do what you would normally do } \\ \text { Second South American } & \text { Accept the circumstance of the assigned role } \\ \text { Conference on the Environment } & \text { - If your group reaches agreement prior to the } \\ \text { deadline then take a longer break }\end{array}$


XIV International Business and Economy Conference

Bangkok, Thailand, January 5-8, 2015

\section{Second South American Conference on the Environment}

Role Assignment (page 1)

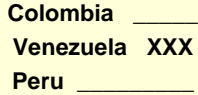

Fixed Costs to Solve a Water Pollution Problem

Technical studies indicate that the cost of building a separate water treatment plant in each country will be:

$\begin{array}{ll}\$ 5,000,000 & \text { Colombia } \\ \$ 3,000,000 & \text { Venezuela } \\ \$ 2,000,000 & \text { Peru }\end{array}$

These differences are due to the amount of pollution discharged by companies in each country.

These numbers are not negotiable (they are fixed throughout the negotiation)

\section{Procedural Rules (See Last Paragraph)}

- Negotiation: $\mathbf{4 0}$ minutes (no agreement $=\$ 0$ savings)

- Any negotiator can propose a private one-on-one meeting (a proposal can be accepted or rejected)

- If private meeting is accepted then two negotiators move away (4 minutes maximum)

- The $3^{\text {rd }}$ negotiator becomes timekeeper (go find them after 4 minutes) but don't forget to do some planning

- Any private two-way agreement must be communicated to the $3^{\text {rd }}$ negotiator (cost-saving division)

- Negotiation over if an agreement stands for $\mathbf{4}$ minutes

- Peru is responsible for recording and reporting outcome

- If you finish early do not disturb other negotiations

- Calculators and watches should be shared

\section{Negotiation Exercise}

\section{$1 \times 1 \times 1$}

(It is better to negotiate with people you do not know. If you move seats take all your possessions with you)

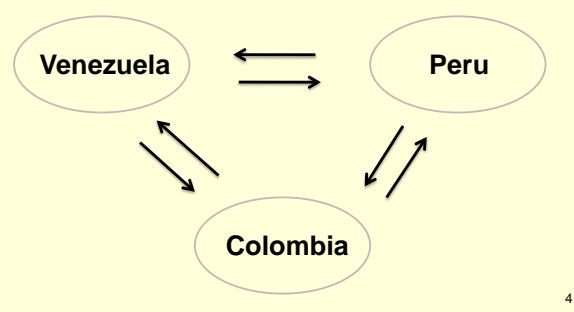

\section{Negotiation is about Savings via} Cooperation (NOT Costs)

The estimated saving for a two-country project or threecountry project are as follows:

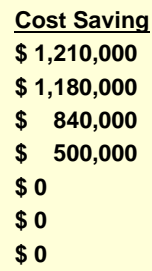

$\quad$ Coalition
Colombia, Venezuela and Peru
Colombia and Venezuela
Colombia and Peru
Venezuela and Peru
Colombia alone
Venezuela alone
Peru alone

Reporting Sheet: Cost Saving Division

(Peru: Submit to Instructor)

Team 7

Colombia Venezuela ${ }^{*}$ Peru Total

\section{Appendix C:}

Debriefing Negotiation Exercise (4 slides)

\section{Debriefing Negotiation Exercise}

Second South American Conference on the Environment
Two Party, Multiparty and Complexity

\begin{tabular}{|c|c|c|}
\hline Peru & $\underline{\text { Venezuela }}$ & \\
\hline$\$ 250,000$ & $\$ 250,000$ & (50/50 - Equality) \\
\hline$\$ 200,000$ & $\$ 300,000$ & (40/60 - Equity) \\
\hline
\end{tabular}

Fairly Predictable - but just add a third party 
XIV International Business and Economy Conference

Bangkok, Thailand, January 5-8, 2015

Three Party Negotiation

Five Possible Outcomes:

No Agreement

Agreement: Colombia and Venezuela

Agreement: Columbia and Peru

Agreement: Venezuela and Peru

Agreement: Colombia, Venezuela and Peru

Multiple Alternatives Increase Complexity

\section{Sources of Power}

Preparation and analysis

Personal knowledge, skill, ability and attributes

Bringing value to the table (Spending by Colombia creates value through increased potential saving and such savings creates inter-dependence)

Strategically applying accepted social norms or principles (Equity Principle, Equality Principle, Margin Principle, Power Principle, Need Principle)

Coalition building (shifts power relations)

Choice of frame (Equity Principle vs. Margin Principle) or strategically imposing a frame on others (cost/savings vs. punishing polluters)

\section{Appendix D:}

Negotiation Exercise Results form

Negotiation Exercise: Results

Second South American Conference on the Environment

\begin{tabular}{|c|c|c|c|}
\hline $\begin{array}{c}\text { Team } \\
\text { Assignment }\end{array}$ & Colombia & Venezuela & Peru \\
\hline Team 1 & & & \\
\hline Team 2 & & & \\
\hline Team 3 & & & \\
\hline
\end{tabular}


XIV International Business and Economy Conference

Bangkok, Thailand, January 5-8, 2015

\begin{tabular}{|l|l|l|l|}
\hline Team 4 & & & \\
\hline Team 5 & & & \\
\hline Team 6 & & & \\
\hline Team 7 & & & \\
\hline Team 8 & & & \\
\hline Team 9 & & & \\
\hline Team 10 & & & \\
\hline Team 11 & & & \\
\hline Team 12 & & & \\
\hline Team 13 & & & \\
\hline Team 14 & & & \\
\hline Team 15 & & & \\
\hline Team 16 & & & \\
\hline Team 17 & & & \\
\hline Team 18 & & & \\
\hline Team 19 & & & \\
\hline Team 20 & & \\
\hline
\end{tabular}

Appendix E:

A Sample of Negotiation Exercise Results

Appendix E1: International Business Negotiation 2011 Second South American Conference on the Environment

\begin{tabular}{|c|r|r|r|}
\hline $\begin{array}{c}\text { Team } \\
\text { Assignment }\end{array}$ & Colombia & Venezuela & \multicolumn{1}{c|}{ Peru } \\
\hline Team 1 & $\mathbf{7 5 0 , 0 0 0}$ & $\mathbf{4 5 0 , 0 0 0}$ & $\mathbf{1 0 , 0 0 0}$ \\
\hline
\end{tabular}




\begin{tabular}{|l|r|r|r|}
\hline Team 2 & $\mathbf{7 4 7 , 5 0 0}$ & $\mathbf{4 4 2 , 5 0 0}$ & $\mathbf{3 0 , 0 0 0}$ \\
\hline Team 3 & $\mathbf{7 2 0 , 0 0 0}$ & $\mathbf{3 6 8 , 0 0 0}$ & $\mathbf{1 2 2 , 0 0 0}$ \\
\hline Team 4 & $\mathbf{7 3 5 , 0 0 0}$ & $\mathbf{4 3 8 , 0 0 0}$ & $\mathbf{3 7 , 0 0 0}$ \\
\hline Team 5 & $\mathbf{6 8 5 , 0 0 0}$ & $\mathbf{3 9 5 , 0 0 0}$ & $\mathbf{1 3 0 , 0 0 0}$ \\
\hline Team 6 & $\mathbf{4 0 3 , 3 3 3}$ & $\mathbf{4 0 3 , 3 3 3}$ & $\mathbf{4 0 3 , 3 3 3}$ \\
\hline Team 7 & $\mathbf{7 0 8 , 0 0 0}$ & $\mathbf{4 7 2 , 0 0 0}$ & $\mathbf{3 0 , 0 0 0}$ \\
\hline Team 8 & $\mathbf{6 7 1 , 2 5 0}$ & $\mathbf{3 7 8 , 7 5 0}$ & $\mathbf{1 6 0 , 0 0 0}$ \\
\hline Team 9 & $\mathbf{6 0 5 , 0 0 0}$ & $\mathbf{4 6 3 , 0 0 0}$ & $\mathbf{1 4 2 , 0 0 0}$ \\
\hline Team 10 & $\mathbf{6 0 0 , 0 0 0}$ & $\mathbf{4 0 0 , 0 0 0}$ & $\mathbf{2 1 0 , 0 0 0}$ \\
\hline Team 11 & $\mathbf{7 8 0 , 0 0 0}$ & $\mathbf{3 7 0 , 0 0 0}$ & $\mathbf{6 0 , 0 0 0}$ \\
\hline Team 12 & $\mathbf{7 1 0 , 0 0 0}$ & $\mathbf{4 3 0 , 0 0 0}$ & $\mathbf{7 0 , 0 0 0}$ \\
\hline Team 13 & $\mathbf{7 0 0 , 0 0 0}$ & $\mathbf{4 2 0 , 0 0 0}$ & $\mathbf{9 0 , 0 0 0}$ \\
\hline Team 14 & $\mathbf{7 3 7 , 5 0 0}$ & $\mathbf{4 4 2 , 5 0 0}$ & $\mathbf{0}$ \\
\hline Team 15 & $\mathbf{4 8 4 , 8 0 0}$ & $\mathbf{4 2 3 , 5 0 0}$ & $\mathbf{3 0 2 , 5 0 0}$ \\
\hline Team 16 & $\mathbf{6 6 0 , 0 0 0}$ & $\mathbf{4 4 0 , 0 0 0}$ & $\mathbf{1 1 0 , 0 0 0}$ \\
\hline Team 17 & $\mathbf{7 4 5 , 0 0 0}$ & $\mathbf{3 6 5 , 0 0 0}$ & $\mathbf{1 0 0 , 0 0 0}$ \\
\hline Team 18 & $\mathbf{6 0 5 , 0 0 0}$ & $\mathbf{3 6 3 , 0 0 0}$ & $\mathbf{2 4 2 , 0 0 0}$ \\
\hline
\end{tabular}

Appendix E2: International Business Negotiation 2012 Second South American Conference on the Environment

\begin{tabular}{|c|r|r|r|}
\hline $\begin{array}{c}\text { Team } \\
\text { Assignment }\end{array}$ & Colombia & Venezuela & \multicolumn{1}{c|}{ Peru } \\
\hline Team 21 & $\mathbf{6 0 5 , 0 0 0}$ & $\mathbf{0}$ & $\mathbf{6 0 5 , 0 0 0}$ \\
\hline Team 22 & $\mathbf{6 0 0 , 0 0 0}$ & $\mathbf{0}$ & $\mathbf{2 4 0 , 0 0 0}$ \\
\hline Team 23 & $\mathbf{7 3 0 , 0 0 0}$ & $\mathbf{4 0 0 , 0 0 0}$ & $\mathbf{8 0 , 0 0 0}$ \\
\hline Team 24 & $\mathbf{7 1 8 , 0 0 0}$ & $\mathbf{4 7 4 , 0 0 0}$ & $\mathbf{1 5 , 0 0 0}$ \\
\hline
\end{tabular}




\begin{tabular}{|l|l|r|r|r|}
\hline Team & 25 & $\mathbf{7 3 7 , 5 0 0}$ & $\mathbf{4 4 1 , 5 0 0}$ & $\mathbf{0}$ \\
\hline Team & $\mathbf{2 6}$ & $\mathbf{7 7 0 , 0 0 0}$ & $\mathbf{3 7 0 , 0 0 0}$ & $\mathbf{7 0 , 0 0 0}$ \\
\hline Team & 27 & $\mathbf{7 3 7 , 5 0 0}$ & $\mathbf{4 4 2 , 5 0 0}$ & $\mathbf{3 0 , 0 0 0}$ \\
\hline Team & 28 & $\mathbf{6 0 0 , 0 0 0}$ & $\mathbf{3 6 5 , 0 0 0}$ & $\mathbf{2 4 5 , 0 0 0}$ \\
\hline Team & 29 & $\mathbf{7 3 7 , 0 0 0}$ & $\mathbf{4 4 2 , 0 0 0}$ & $\mathbf{3 1 , 0 0 0}$ \\
\hline Team & 30 & $\mathbf{6 0 5 , 0 0 0}$ & $\mathbf{3 6 3 , 0 0 0}$ & $\mathbf{2 4 0 , 0 0 0}$ \\
\hline Team & 31 & $\mathbf{8 3 5 , 0 0 0}$ & $\mathbf{3 4 5 , 0 0 0}$ & $\mathbf{0}$ \\
\hline Team & 32 & $\mathbf{7 0 5 , 0 0 0}$ & $\mathbf{3 0 5 , 0 0 0}$ & $\mathbf{2 0 0 , 0 0 0}$ \\
\hline Team & 33 & $\mathbf{8 4 0 , 0 0 0}$ & $\mathbf{3 4 0 , 0 0 0}$ & $\mathbf{0}$ \\
\hline Team & 34 & $\mathbf{7 6 0 , 0 0 0}$ & $\mathbf{3 9 0 , 0 0 0}$ & $\mathbf{6 0 , 0 0 0}$ \\
\hline Team & 35 & $\mathbf{6 5 0 , 0 0 0}$ & $\mathbf{3 6 0 , 0 0 0}$ & $\mathbf{2 0 0 , 0 0 0}$ \\
\hline
\end{tabular}

Appendix E3: International Business Negotiation 2013 Second South American Conference on the Environment

\begin{tabular}{|r|r|r|r|}
\hline $\begin{array}{c}\text { Team } \\
\text { Assignment }\end{array}$ & \multicolumn{1}{|c|}{ Colombia } & Venezuela & \multicolumn{1}{c|}{ Peru } \\
\hline Team 41 & $\mathbf{7 0 5 , 0 0 0}$ & $\mathbf{4 0 3 , 0 0 0}$ & $\mathbf{1 0 2 , 0 0 0}$ \\
\hline Team 42 & $\mathbf{5 0 0 , 0 0 0}$ & $\mathbf{3 0 0 , 0 0 0}$ & $\mathbf{4 1 0 , 0 0 0}$ \\
\hline Team 43 & $\mathbf{6 0 5 , 0 0 0}$ & $\mathbf{3 6 3 , 0 0 0}$ & $\mathbf{2 4 2 , 0 0 0}$ \\
\hline Team 44 & $\mathbf{6 0 5 , 0 0 0}$ & $\mathbf{3 6 3 , 0 0 0}$ & $\mathbf{2 4 2 , 0 0 0}$ \\
\hline
\end{tabular}




\begin{tabular}{|l|l|r|r|r|}
\hline Team & 45 & $\mathbf{6 6 5 , 5 0 0}$ & $\mathbf{4 2 3 , 5 0 0}$ & $\mathbf{1 2 1 , 0 0 0}$ \\
\hline Team & 46 & $\mathbf{6 0 5 , 0 0 0}$ & $\mathbf{3 6 3 , 0 0 0}$ & $\mathbf{2 4 2 , 0 0 0}$ \\
\hline Team & 47 & $\mathbf{6 0 5 , 0 0 0}$ & $\mathbf{6 0 5 , 0 0 0}$ & $\mathbf{0}$ \\
\hline Team & 48 & $\mathbf{6 0 5 , 0 0 0}$ & $\mathbf{3 6 3 , 0 0 0}$ & $\mathbf{2 4 2 , 0 0 0}$ \\
\hline Team & 49 & $\mathbf{6 0 5 , 0 0 0}$ & $\mathbf{3 6 3 , 0 0 0}$ & $\mathbf{2 4 2 , 0 0 0}$ \\
\hline Team & $\mathbf{5 0}$ & $\mathbf{4 8 4 , 0 0 0}$ & $\mathbf{4 8 4 , 0 0 0}$ & $\mathbf{2 4 2 , 0 0 0}$ \\
\hline Team & $\mathbf{5 1}$ & $\mathbf{5 4 6 , 0 0 0}$ & $\mathbf{4 7 2 , 0 0 0}$ & $\mathbf{1 9 2 , 0 0 0}$ \\
\hline Team & $\mathbf{5 2}$ & $\mathbf{6 0 5 , 0 0 0}$ & $\mathbf{3 6 3 , 0 0 0}$ & $\mathbf{2 4 2 , 0 0 0}$ \\
\hline Team & $\mathbf{5 3}$ & $\mathbf{6 0 5 , 0 0 0}$ & $\mathbf{3 6 3 , 0 0 0}$ & $\mathbf{2 4 2 , 0 0 0}$ \\
\hline Team & $\mathbf{5 4}$ & $\mathbf{4 0 3 , 3 3 3}$ & $\mathbf{4 0 3 , 3 3 3}$ & $\mathbf{4 0 3 , 3 3 3}$ \\
\hline Team & $\mathbf{5 5}$ & $\mathbf{7 5 6 , 2 5 0}$ & $\mathbf{4 5 3 , 7 5 0}$ & $\mathbf{0}$ \\
\hline Team & $\mathbf{5 6}$ & $\mathbf{6 0 5 , 0 0 0}$ & $\mathbf{3 6 3 , 0 0 0}$ & $\mathbf{2 4 2 , 0 0 0}$ \\
\hline Team & 57 & $\mathbf{7 1 0 , 8 7 5}$ & $\mathbf{4 2 6 , 5 2 5}$ & $\mathbf{7 2 , 6 0 0}$ \\
\hline Team & $\mathbf{5 8}$ & $\mathbf{7 0 0 , 0 0 0}$ & $\mathbf{4 3 0 , 0 0 0}$ & $\mathbf{8 0 , 0 0 0}$ \\
\hline
\end{tabular}

\section{SECOND SOUTH AMERICAN CONFERENCE ON THE ENVIRONMENT*} Role Information for All Parties (No Confidential Information in this Exercise)

At the $1^{\text {st }}$ South American Conference on the Environment, the 14 member nations reached an agreement on the need for action, especially related to water quality in rural communities, agricultural districts and urban areas. Three years later, these 14 nations convened the $2^{\text {nd }}$ South American Conference on the Environment. Brazil was strongest in advocating for a second conference that would move beyond a declaration of political will and toward establishing an action program focused on water quality. Brazil is convening this $2^{\text {nd }}$ conference in Brasilia, and its Foreign Minister is the Conference Presiding Officer.

The Committee on the Amazon River is the most important committees at the Conference, with a large mandate, seven Working Groups and Brazil serving as Committee Chair.

You are a member of the Working Group on the Amazon Upper-Tributary River System. This Working Group includes representatives of three countries - Colombia, Venezuela and Peru - and is also chaired by a representative of Brazil. 
Leather factories in each of these three countries are dumping chemical waste into rivers that feed into the Negro River, which eventually flows into the Amazon River. Most of the Negro and Amazon flow through Brazil, while the point at which the Negro meets the Amazon is at Manaus in Brazil. After many long and heated meetings, the Brazilin Chair of this Working Group walked out in disgust, but departed with a threat: Colombia, Venezuela and Peru must find a solution to the Negro River's pollution problems. Brazil is the most powerful country in South America, and could cause difficulties for these nations in security, trade and international cooperation. It is obvious that a response is required. Your Foreign Minister (your supervisor) is adamant that a solution must be found. You are representing:

Colombia Venezuela Peru

Economic studies point out that one large water treatment plant on the Upper Negro River would be less expensive than each of the three countries building a separate water treatment plant on its respective tributary. In addition, it is also possible that any two of the three countries could build a water treatment plant that would provide a solution for these two countries, while the third country would be forced to build its own water treatment plant. Technical studies indicate that the cost of building a separate water treatment plant in each country will be:

$\$ 5,000,000$ Colombia

$\$ 3,000,000$ Venezuela

$\$ 2,000,000$ Peru

These differences are due to the amount of pollution discharged by companies in each country.

At the $1^{\text {st }}$ South American Conference on the Environment, the Formal Declaration indicated that legal obstacles to international cooperation should be minimized. The Committee on Law and the Environment at the $2^{\text {nd }}$ Conference has completed its work and the Conference Plenary has adopted its recommendations. As a result, there are no legal reasons why two or three countries cannot work together, although there is also no legal requirement that forces countries to cooperate.

* This negotiation exercise was written by Larry Crump (Department of International Business, Griffith University, Brisbane Australia: L.Crump@griffith.edu.au) based on a concept developed by Howard Raiffa (see "Coalition Analysis" in The Art and Science of Negotiation, Harvard University Press, 1982).

The Working Group on the Amazon Upper-Tributary River System has conducted an engineering study that indicates that substantial savings in construction costs will be realized through cooperation (constructing one water treatment plant rather than two or three plants). The estimated saving for a two-country project or threecountry project is as follows:

\section{Cost SavingCoalition}

\$1,180,000Colombia and Venezuela

\$ 840,000Colombia and Peru

\$ 500,000Venezuela and Peru

\$1,210,000Colombia, Venezuela and Peru

$\$ 0$ Colombia alone

$\$ 0$ Venezuela alone

$\$$ 0Peru alone

The cost per litre of operating any of the water treatment plant(s) remains the same, compared with operating an individual plant. Operating cost is not an issue in this negotiation.

The three countries have no competitive, non-monetary or political reason to avoid cooperation if it will save them money, nor do they have any reason except for cost savings to work together on this project. The 
representative of each country has been instructed to maximize savings, as the leather industry in each country is politically powerful; it is therefore not expected that a special tax will be levied on this industrial sector.

This negotiation is about saving money, and how much money your country can save compared with your fixed costs. Your task is to meet with the representatives of the other two countries, separately or together, to work out the best deal for your own country (the Foreign Minister of your country is aware of the possible cost savings based on the engineering study). You must agree on a specific cost-saving coalition AND on how the actual saving will be divided among the members of the coalition.

For example, if a coalition of Colombia and Venezuela were to form, it would gain joint savings of \$1,180,000. These two countries could agree to give $\$ 800,000$ to Colombia and $\$ 380,000$ to Venezuela. However, Venezuela might want more from that coalition, and to achieve greater savings might also seek to cooperate with Peru. Since Peru will save nothing unless it joins with Colombia or Venezuela or both, Peru should be very willing to consider various proposals to become involved in a two-way or three-way coalition. Each country should be prepared to make proposals to any other country or both countries.

This negotiation will proceed for exactly 40 minutes. At the start of the negotiation, all three representatives will be at the same table, but then any representative can propose to meet privately with another representative (such proposals can be accepted or rejected). If two representatives agree to meet privately, they must (1) advise the excluded representative of this meeting, (2) advise the excluded representative where they will be meeting, and (3) note the exact time. The excluded representative is forbidden to interrupt this two-way meeting for exactly four minutes (an excluded representative is the timekeeper). If a two-way agreement is reached, it must be clearly communicated immediately to the excluded representative, and from that moment the agreement must endure for four minutes before all three representatives can conclude that negotiations are finished and that the mandate of the Working Group on the Amazon Upper-Tributary River System has been achieved. Good luck!

Working Group Final Report: List the cost savings per country if agreement was reached:

Colombia \$

+ Venezuela $\$$

+ Peru $\$$ $=$ Total $\$$ 